\title{
A Cross-Sectional Study to Determine the Prevalence of Gastroesophageal Reflux in Children with Persistent Cough and Wheezing
}

\author{
Praveen P N ${ }^{\circledR}$, Kushvanth K N ${ }^{\circledR 2}$, Ashish Mallige ${ }^{\circledR 3}$ \\ 1Junior Consultant, Department of Pediatrics, Indira Gandhi Institute of Child Health, Bengaluru, Karnataka, India, ${ }^{2}$ Senior Resident, Department of Pediatrics, St John \\ Medical College, Bengaluru, Karnataka, India, ${ }^{3}$ Senior Resident, Department of Pediatrics, St John Medical College, Bengaluru, Karnataka, India.
}

\section{Abstract}

Background: Gastroesophageal reflux (GER) occurs in more than two-thirds of otherwise healthy infants and is the topic of discussion with pediatricians at one-quarter of all routine 6-month infant visits. GER is considered a normal physiologic process that occurs several times a day in healthy infants, children, and adults. GER is generally associated with transient relaxations of the lower esophageal sphincter independent of swallowing, which permits gastric contents to enter the esophagus. The Objective to find out the prevalence of GER in children with cough and wheezing and its associated factors. Subjects and Methods: A cross-sectional study was done at A tertiary care hospital at the Institute of Naval Medicine, INHS, Mumbai from August 2016 to December 2017. A total of 30 study subjects Aged between the age of one to twelve years with persistent cough and wheezing lasting for more than three months despite treatment were included for the study. Results: The prevalence of gastroesophageal reflux (GER) in our study was 63.3\%.The logistic regression analysis showed that Age, Height, Weight, BMI, duration of cough, Duration of asthma were not significantly associated with Gastroesophageal reflux (GER) ( $>0.05$ ). Conclusion: GER seems to have a high prevalence in children with chronic cough. However, no definite recommendations can be made regarding the management of such cases from our study.

Keywords: Gastric Reflux, Cough, Asthma, Heart Burn

Corresponding Author: Kushvanth K N, Senior Resident, Department of Pediatrics, St John Medical College, Bengaluru, Karnataka, India. E-mail: kushvanth99@gmail.com

Received: 06 September 2020

Revised: 22 October 2020

Accepted: 30 October 2020

Published: 28 December 2020

\section{Introduction}

In approximately more than two-thirds of children gastroesophageal reflux is seen and one of the major conditions seen by pediatrician especially among the 6-month infant visit $^{[1,2]} \mathrm{A}$ part from seeking guidance from the pediatrician about this condition parents also want to be evaluated by Pediatrician Medical Subspecialists. ${ }^{[3]}$ The state-of-the-art approaches to the evaluation and management based on evidence-based guidelines for pediatric GER have been welcomed by both general pediatricians and pediatric medical subspecialists and surgical specialists. Gastroesophageal reflux is said when the gastric contents pass on to the esophagus and it can be distinguished from gastroesophageal reflux disease where it also includes troublesome symptoms or complications along with GER. ${ }^{[4]}$ Differentiating between GER and GERD lies at the crux of the guidelines jointly developed by the North American Society for Pediatric Gastroenterology, Hepatology, and Nutrition and the European Society for Pediatric Gastroenterology, Hepatology, and Nutrition. ${ }^{[4]}$ These definitions have further been recognized as representing a global consensus. ${ }^{[5]}$

GER is a normal physiological phenomenon that can be seen many times in a 24-hour cycle among healthy infants, children and even among adults. GER is often presented with intermittent relaxation in the lower esophageal sphincter irrespective of swallowing which permits gastric contents to enter the esophagus. Among adults, it usually occurs after the meals and will be for 3 minutes duration and can cause symptoms sometimes. ${ }^{[4,6,7]}$ Wher eas the Physiological GER with regurgitation or spitting up among infants and children occurs very often in more than $50 \%$ of the individuals and very less information is available. ${ }^{[7,8]}$ Hence the present study was done at our tertiary care center to the prevalence of GER in children with cough and wheezing for a period of three months or more using precise diagnostic tools like Gastroesophageal scintigraphy. 


\section{Objective}

To find out the prevalence of GER in children with cough and wheezing and its associated factors.

\section{Subjects and Methods}

A Cross-Sectional study was conducted in a tertiary care hospital at the Institute of Naval Medicine, INHS, and Mumbai from August 2016 to December 2017.

The sample size was calculated using the form from Standard Normal Distribution table (1.96) with the Power $(p)=80 \%$ and Precision error of estimation $(\mathrm{d})=0.07 \mathrm{n}=[1.96 \times 1.96 \times 0.8$ $(0.2)] / 0.7 \times 0.7=29.46$.

Hence a sample size of 30 cases was considered adequate for our study.

A total of 30 Children of age $1-12$ years with cough and wheezing presenting to the Pediatric OPD were included in the study.

\section{Inclusion criteria}

Children between the age of one to twelve years with persistent cough and wheezing lasting for more than three months despite treatment. 71

\section{Exclusion criteria}

a. Children with known neurological co-morbidity associated with increased incidence GER

b. Children with known congenital gastrointestinal, esophageal and pulmonary anomalies

c. Children who have undergone surgical or endoscopic intervention involving the esophagus

All children who met the inclusion criteria during the study period after due consent from parents underwent the following:

a) Demographic evaluation,

b) History related to gastroesophageal reflux (GER) symptoms

c) Milk scan/RA scans studies at the nuclear medicine department.

Quantitative variables were analyzed by unpaired't' test and qualitative variables were analyzed using the Chi-square test and Logistic regression. SSPS (Ver 22) and Epi info 7 were used for statistic analysis.

Data were analyzed and quantitative variables were analyzed using unpaired t-test and chi square was used for Qualitative Variables. A p-value of less than 0.05 was considered to be significant.

\section{Results}

Total of 30 Children were included in the study and analyzed

\begin{tabular}{|c|c|c|c|}
\hline \multirow{2}{*}{\multicolumn{2}{|c|}{ Demographic }} & \multicolumn{2}{|l|}{ Age Group } \\
\hline & & $<5$ years & $>5$ Years \\
\hline \multirow[t]{2}{*}{ Gender } & Male & $11(36.6 \%)$ & $10(33.3 \%)$ \\
\hline & Female & $3(10 \%)$ & $6(20 \%)$ \\
\hline \multicolumn{2}{|c|}{ Mean Weight in Kg } & $16.2+2.77$ & $31.3+7.05$ \\
\hline \multicolumn{2}{|c|}{ Mean Height in $\mathrm{Cm}$} & $97.7+7.8$ & $131.3+11.72$ \\
\hline \multicolumn{2}{|c|}{ Mean BMI } & $16.97+2.12$ & $18.15+3.13$ \\
\hline
\end{tabular}

The Mean Height, Weight and BMI among the study subjects were found to be within the normal range.

\begin{tabular}{|c|c|c|c|}
\hline \multirow[t]{2}{*}{ Symptoms } & \multicolumn{3}{|c|}{ Age groups } \\
\hline & $<5$ years & $\begin{array}{l}5-10 \\
\text { years }\end{array}$ & $>10$ Years \\
\hline Vomiting & $8(57 \%)$ & $8(72 \%)$ & $2(40 \%)$ \\
\hline Excessive Crying & $5(35.7 \%)$ & $3(27.2 \%)$ & $1(20 \%)$ \\
\hline Wakes up at night & $8(57 \%)$ & $10(91 \%)$ & $3(60 \%)$ \\
\hline $\begin{array}{l}\text { Heart Burns/Chest } \\
\text { Pain }\end{array}$ & $1(7.1 \%)$ & $2(18 \%)$ & $4(80 \%)$ \\
\hline Abdomen Pain & $7(50 \%)$ & $3(27.2 \%)$ & $2(40 \%)$ \\
\hline $\begin{array}{l}\text { Arching back in } \\
\text { pain }\end{array}$ & $1(7.1 \%)$ & & \\
\hline Refuses to eat & $13(92.8 \%)$ & $5(45.5 \%)$ & $2(40 \%)$ \\
\hline Hoarse Voice & & $1(9 \%)$ & $2(40 \%)$ \\
\hline Weight Loss & $3(21.4 \%)$ & $1(9 \%)$ & $1(20 \%)$ \\
\hline Asthma & $5(35.7 \%)$ & $7(63.6 \%)$ & $1(20 \%)$ \\
\hline
\end{tabular}

In the age group, less than 5 years most common symptom was a refusal to eat $(92.8 \%)$, the second common symptom was vomiting and waking up at night due to cough (57\%). In the age group between 5 years to 10 years most common symptom was waking up at night due to cough (91\%), the second common symptom was vomiting $(72 \%)$. In the age group, more than 10 years most common symptom was heartburn/ chest pain $(80 \%)$, the second common symptom was waking up at night due to cough $(60 \%)$.

Table 3: Prevalence of Gastro-Esophageal Reflux (GER) on Scintigraphy

\begin{tabular}{lll}
\hline Prevalence of GER & $\mathbf{N}$ & $\mathbf{\%}$ \\
\hline Positive & 19 & $63.3 \%$ \\
\hline Negative & 11 & $36.7 \%$ \\
\hline Total & 30 & $100 \%$ \\
\hline
\end{tabular}




\begin{tabular}{|c|c|c|c|c|c|c|}
\hline & & \multicolumn{2}{|c|}{ Positive } & \multicolumn{2}{|c|}{ Negative } & \multirow[t]{2}{*}{ P-value } \\
\hline & & $\mathbf{N}$ & $\%$ & $\mathbf{N}$ & $\%$ & \\
\hline \multirow[t]{2}{*}{ Age Group } & $<5$ years & 12 & 40 & 6 & 20 & 0.642 \\
\hline & $>5$ Years & 7 & 23.3 & 5 & 16.7 & \\
\hline \multirow[t]{2}{*}{ Gender } & Male & 12 & 63.15 & 9 & 81.8 & 0.29 \\
\hline & Female & 7 & 36.85 & 2 & 18.18 & \\
\hline \multirow[t]{2}{*}{ Duration of Cough } & $<5$ Months & 13 & 68.42 & 7 & 63.63 & 0.78 \\
\hline & $>5$ Months & 6 & 31.58 & 4 & 36.37 & \\
\hline \multirow[t]{2}{*}{ Asthma } & Yes & 9 & 30 & 4 & 13.3 & 0.557 \\
\hline & No & 10 & 33.3 & 7 & 23.4 & \\
\hline Vomiting & & 11 & 61.1 & 7 & 38.9 & 0.75 \\
\hline Heart Burns/Chest Pain & & 4 & 57.1 & 3 & 42.9 & 0.69 \\
\hline Weight Loss & & 3 & 60 & 2 & 40 & 0.86 \\
\hline
\end{tabular}

The prevalence of gastroesophageal reflux (GER) in our study was $63.3 \%$.

The majority of cases with Gastroesophageal reflux (GER) (12 out of $19 ; 40 \%$ ) were in the age group of fewer than 5 years than more than 5 years ( 5 out of $19 ; 23.3 \%)$. It was observed that $12(63 \%)$ male and $7(36.85 \%)$ female cases had GER. The majority of cases with Gastroesophageal reflux (GER) (15 out of $19 ; 50 \%$ ) had coughs for less than 5 months. It was observed that $47.3 \%$ of cases with Gastroesophageal reflux (GER) (9 out of 19\%) had asthma. There is no significant association between symptoms and gastroesophageal reflux.

The logistic regression analysis showed that Age, Height, Weight, BMI, duration of cough, Duration of asthma were not significantly associated with Gastroesophageal reflux (GER) $(\mathrm{p}>0.05)$.

\section{Discussion}

Gastroesophageal reflux (GER), defined as the passage of gastric contents into the esophagus, is distinguished from gastroesophageal reflux disease (GERD), which includes troublesome symptoms or complications associated with GER. ${ }^{[4]}$ Children with gastro-oesophageal reflux (GER) present with oesophageal and extra-oesophageal symptoms. Chronic cough and recurrent wheezing are the common extra oesophageal respiratory symptoms of GER. Children with GER have a very wide spectrum varying in infants as a physiological process and in children and adolescents as pathological sequelae comprising the well-known entity Gastro-Esophageal Reflux Disease. ${ }^{[1]}$ In a study from Australia, by Shepherd et al, ${ }^{[9]}$ the most common symptom was vomiting $(98.4 \%)$ followed by a refusal to eat (51.6\%). The least symptom was 'arching back in pain' $(7.9 \%)$. In our study, the most common symptom was waking up at night due to cough (70\%) followed by a refusal to eat $(66.6 \%)$. The least symptom was 'arching back in pain' $(3.3 \%)$. The difference in symptom percentage of Shepherd Locke et al, ${ }^{[9]}$ from the present study may be due to the difference in the age group of the study population (included infants in the study group). In a study from Philadelphia, by Linda deal et al, ${ }^{[10]}$ the most common symptom was waking up at night due to cough $(67.16 \%)$ similar to the present study (70\%). The second most common symptom was a refusal to eat $(47.7 \%)$. The least common symptom was 'arching back in pain' (4.4\%) similar to the present study (4.4\%). In a study from India, by Bhatia et al, ${ }^{[11]}$ heart burns/chest pain symptom was present in $12.72 \%$ and abdominal pain in $10 \%$ of the population. In the present study heart, burns/chest pain symptoms were present in $23.3 \%$ and abdominal pain in $40 \%$ of the study population (Table 16). The difference in the percentage of symptoms may be due to the fact that Bhatia et al's, ${ }^{[11]}$ study involves the adult age group. In a study from Norway, by Ketil Stordal et al, ${ }^{[12]}$ heartburns/chest pain symptom was present in $22.2 \%$ population and abdominal pain in $75.75 \%$ population. The difference in the percentage of symptoms of heartburn/chest pain was negligible and the difference in the percentage of symptom abdominal pain may be due to the fact that in Ketil Stordal et al, ${ }^{[12]}$ study, the numbers were more compared to the present study and study population also involved the adolescents (10-17 years). In a study from the USA, by Poe et $a l,{ }^{[13]} 35 \%$ of the study population were asthmatic in chronic chough. The difference in the percentage of the asthmatic population may be due to Poe et al's, ${ }^{[13]}$ study includes the adolescent age group. In studies done, by Irwin RS et al, ${ }^{[14]}$ and Shirahata K et al, ${ }^{[15]} 43 \%$ and $42 \%$ of the study population were asthmatic in chronic chough. The asthmatic population in the chronic cough of the present study was comparable with the mentioned studies. In a study from Boston, 


\begin{tabular}{|c|c|c|c|c|}
\hline \multirow[t]{2}{*}{ Parameters } & \multirow[t]{2}{*}{ p-Value (Logistic regression) } & \multirow[t]{2}{*}{$\operatorname{Exp}(\beta)$} & \multicolumn{2}{|c|}{ 95\% C.I. for $\operatorname{Exp}(\beta)$} \\
\hline & & & Lower & Upper \\
\hline Age & 0.096 & 0.255 & 0.051 & 1.272 \\
\hline Height & 0.082 & 1.475 & 0.952 & 2.285 \\
\hline Weight & 0.444 & 0.741 & 0.344 & 1.595 \\
\hline BMI & 0.421 & 1.571 & 0.523 & 4.723 \\
\hline Duration of Cough & 0.204 & 0.700 & 0.405 & 1.213 \\
\hline Duration of Asthma & 0.216 & 0.899 & 0.759 & 1.064 \\
\hline
\end{tabular}

by Irwin et al, ${ }^{[14]}$ prevalence of gastroesophageal reflux in chronic cough was $100 \%$. In the present study prevalence of gastroesophageal reflux was $63.3 \%$. The difference in prevalence may be due to the study population in Irwin et al, ${ }^{[14]}$ was less and the cut-off duration for chronic cough was taken only three weeks as compared to the present study. In a study from Saudi Arabia, by Saleh Othman et al, ${ }^{[16]}$ prevalence of gastroesophageal reflux in chronic cough was $43.8 \%$. Studies done by, Khoshoo et al, ${ }^{[17]}$ and Mardjanis Said et al ${ }_{[18]}$ showed no significant association between age and gastroesophageal reflux similar to the present study. Studies were done by, Khoshoo et al, ${ }^{[17]}$ and Mardjanis Said et al, ${ }^{[18]}$ showed no significant association between gender and gastroesophageal reflux as similar to the present study. Studies were done by Irwin RS et $a{ }^{,}{ }^{[14]}$ and Shirahata $\mathrm{K}$ et al, ${ }^{[15]}$ showed no significant association between asthma and gastroesophageal reflux similar to the present study.

\section{Conclusion}

The strength of the present study is that it was conducted in a tertiary care set- up with in-house availability of required investigations where there was a high number of chronic cough cases being managed. This can explain the exceptionally high prevalence of GER (63.3\%) in our study. Scintigraphy is often used to rule out GER in chronic cough in children before doing an invasive, extensive and expensive investigation to avoid psychological and financial burden on parents. In summary, GER seems to have a high prevalence in children with chronic cough. However, no definite recommendations can be made regarding the management of such cases from our study.

\section{References}

1. Nelson SP, Chen EH, Syniar GM, Christoffel KK, Group PPR. Prevalence of symptoms of gastroesophageal reflux during childhood: a pediatric practice-based survey. Arch Pediatr Adolesc Med. 2000;154(2):150-154. Available from: https: //doi.org/10.1001/archpedi.154.2.150.

2. Campanozzi A, Boccia G, Pensabene L, Panetta F, Marseglia A, Strisciuglio P, et al. Prevalence and Natural History of
Gastroesophageal Reflux: Pediatric Prospective Survey. Pediat. 2009;123(3):779-783. Available from: https://dx.doi.org/10. 1542/peds.2007-3569.

3. Shalaby TM, Orenstein SR. Efficacy of telephone teaching of conservative therapy for infants with symptomatic gastroesophageal reflux referred by pediatricians to pediatric gastroenterologists. J Pediatr. 2003;142(1):57-61. Available from: https://dx.doi.org/10.1067/mpd.2003.mpd0331.

4. Vandenplas Y, Rudolph CD, Lorenzo D, C. Pediatric gastroesophageal reflux clinical practice guidelines: joint recommendations of the North American Society for Pediatric Gastroenterology, Hepatology, and Nutrition (NASPGHAN) and the European Society for Pediatric Gastroenterology, Hepatology, and Nutrition (ESPGHAN). J Pediatr Gastroenterol Nutr. 2009;49(4):498-547.

5. Sherman PM, Hassall E, Fagundes-Neto U, Gold BD, Kato S, Koletzko S, et al. A Global, Evidence-Based Consensus on the Definition of Gastroesophageal Reflux Disease in the Pediatric Population. Am J Gastroenterol. 2009;104(5):1278-1295. Available from: https://dx.doi.org/10.1038/ajg.2009.129.

6. Shay S, Tutuian R, Sifrim D, Vela M, Wise J, Balaji N, et al. Twenty-Four Hour Ambulatory Simultaneous Impedance and pH Monitoring: A Multicenter Report of Normal Values From 60 Healthy Volunteers. Am J Gastroenterol. 2004;99(6):10371043. Available from: https://dx.doi.org/10.1111/j.1572-0241. 2004.04172.x.

7. Rudolph CD, Mazur LJ, Liptak GS. North American Society for Pediatric Gastroenterology and Nutrition. Guidelines for evaluation and treatment of gastroesophageal reflux in infants and children: recommendations of the North American Society for Pediatric Gastroenterology and Nutrition. J Pediatr Gastroenterol Nutr. 2001;32(2):1-31. Available from: https: //doi.org/10.1097/00005176-200100002-00001.

8. Martin AJ, Pratt N, Kennedy JD, Ryan P, Ruffin RE, Miles $\mathrm{H}$, et al. Natural History and Familial Relationships of Infant Spilling to 9 Years of Age. Pediatrics. 2002;109(6):1061-1067. Available from: https://dx.doi.org/10.1542/peds.109.6.1061.

9. Shepherd R, Wren J, Evan S, Lander M, Ong T. Gastroesophageal reflux in children. Clinical profile, course and outcome with active therapy in 126 cases. Clinical Pediatrics. 1987;26(2):55-60. Available from: https://dx.doi.org/10.1177/ 000992288702600201.

10. Deal L, Gold BD, Gremse DA, Winter HS, Peters SB, Fraga PD, et al. Age-Specific Questionnaires Distinguish 
GERD Symptom Frequency and Severity in Infants and Young Children: Development and Initial Validation. J Pediatr Gastroenterol Nutr. 2005;41(2):178-185. Available from: https://dx.doi.org/10.1097/01.mpg.0000172885.77795.0f.

11. Shobna J, \&amp; D Nageshwar Reddy \&amp; Uday CB. Ghoshal et al Epidemiology and symptom profile of gastroesophageal reflux in the Indian population: report of the Indian Society of Gastroenterology Task Force. Indian J Gastroenterol. 2011;30(3):118-127. Available from: https://doi.org/10. 1007/s12664-011-0112-x.

12. Størdal K, Johannesdottir GB, Bentsen BS, Sandvik L. Gastroesophageal reflux disease in children: Association between symptoms and $\mathrm{pH}$ monitoring. Scand $\mathrm{J}$ Gastroenterol. 2005;40(6):636-640. Available from: https://dx.doi.org/10. 1080/00365520510015502.

13. Poe RH, Harder RV, Israel RH, Kallay MC. Chronic persistent cough. Experience in diagnosis and outcome using an anatomic diagnostic protocol. Chest. 1989;95(4):723-751. Available from: https://doi.org/10.1378/chest.95.4.723.

14. Irwin RS, Corrao WM, Pratter MR. Chronic persistent cough: the spectrum and frequency of causes and successful outcome of specific therapy. Am Rev Respir Dis. 1981;123(4):413-430. Available from: https://doi.org/10.1164/arrd.1981.123.4.413.

15. Shirahata K, Fujimoto K, Arioka H, Shouda R, Kudo K, ichi Ikeda S. Prevalence and clinical features of cough variant asthma in a general internal medicine outpatient clinic in Japan. Respirology. 2005;10(3):354-358. Available from: https://dx. doi.org/10.1111/j.1440-1843.2005.00709.x.
16. Othman S. Saleh Othman Gastroesophageal reflux studies using milk in infants and children - the need for multiple views Nuclear Medicine Communications; 2011. Available from: https://doi.org/10.1097/mnm.0b013e32834a0b0d.

17. Khoshoo V, Edell D, Mohnot S, Haydel R, Saturno E, Kobernick A. Associated Factors in Children With Chronic Cough. Chest. 2009;136(3):811-815. Available from: https: //dx.doi.org/10.1378/chest.09-0649.

18. Said M, Syamsu R, Tambunan T, Hegar B. Gastroesophageal reflux in children with chronic recurrent cough. Paediatrica Indonesiana. 2004;44(5):1-10. Available from: https://doi.org/ 10.14238/pi44.5.2004.201-5.

Copyright: (C) the author(s), 2020. It is an open-access article distributed under the terms of the Creative Commons Attribution License (CC BY 4.0), which permits authors to retain ownership of the copyright for their content, and allow anyone to download, reuse, reprint, modify, distribute and/or copy the content as long as the original authors and source are cited.

How to cite this article: P N P, K N K, Mallige A. A CrossSectional Study to Determine the Prevalence of Gastroesophageal Reflux in Children with Persistent Cough and Wheezing. Asian J. Clin. Pediatr. Neonatol. 2020;8(4):36-40.

DOI: dx.doi.org/10.47009/ajcpn.2020.8.4.8

Source of Support: Nil, Conflict of Interest: None declared.

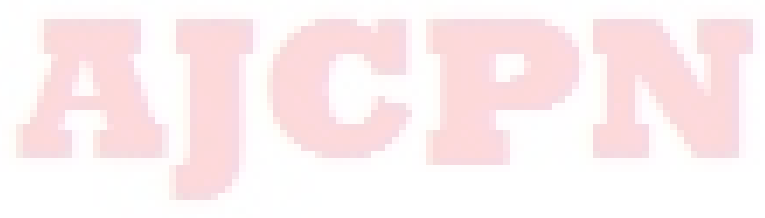

